\title{
Development of microsatellite markers for a hard-shelled mussel, Mytilus coruscus, and cross-species transfer
}

\author{
J.H. Kang ${ }^{1}$, Y.K. Kim ${ }^{1}$, J.Y. Park ${ }^{1}$, E.S. Noh ${ }^{1}$, J.E. Jeong ${ }^{2}$, Y.S. Lee ${ }^{2}$ and \\ T.J. Choi ${ }^{3}$ \\ 'Biotechnology Research Division, \\ National Fisheries Research and Development Institute, Busan, \\ Republic of Korea \\ ${ }^{2}$ Department of Life Science and Biotechnology, Soonchunhyang University, \\ Asan, Republic of Korea \\ ${ }^{3}$ Department of Microbiology, Pukyong National University, Busan, \\ Republic of Korea \\ Corresponding author: T.J. Choi \\ E-mail: choitj@pknu.ac.kr
}

Genet. Mol. Res. 12 (3): 4009-4017 (2013)

Received February 18, 2013

Accepted July 5, 2013

Published September 27, 2013

DOI http://dx.doi.org/10.4238/2013.September.27.2

\begin{abstract}
The Korean mussel Mytilus coruscus, an endemic marine bivalve mollusk, is economically important. Its population is currently decreasing due to overexploitation and invasion of a more competitive species, Mytilus galloprovincialis. In this study, microsatellite markers for $M$. coruscus were developed using a cost-effective pyrosequencing technique. Among the 33,859 dinucleotide microsatellite sequences identified, 176 loci that contained more than $8 \mathrm{CA}, \mathrm{CT}$, or AT repeats were selected for primer synthesis. Sixty-four (36.4\%) primer sets were produced from the 100- to 200-bp polymerase chain reaction products obtained from $2 \mathrm{M}$. coruscus individuals. Twenty of these were chosen to amplify DNA from $82 \mathrm{M}$. coruscus individuals, and 18 polymorphic loci and 2 monomorphic loci were selected as microsatellite markers. The number of alleles and the allele richness of the polymorphic loci ranged from 2 to 22 and from 2.0 to 19.7 with means of 10.8 and 10.1,
\end{abstract}


respectively. Null alleles were detected for all but three loci, which resulted in an observed heterozygosity lower than the expected heterozygosity and therefore an excess of homozygotes. In a cross-species transfer analysis of these markers using 7 Mytilidae species, the locus Mc65 was amplified from all species tested and was found to be polymorphic in all of them. Among the species, M. galloprovincialis, Lithophaga curta, and Hormomya mutabilis showed the same transferability of $25 \%$, but the five amplified loci were polymorphic only in M. galloprovincialis and $H$. mutabilis. These microsatellite markers may be useful for future resource management and artificial production of juveniles for aquaculture.

Key words: Mytilus coruscus; Microsatellite; Cross-species transfer; Pyrosequencing

\section{INTRODUCTION}

Mytilus coruscus, the Korean or hard-shelled mussel, is a marine bivalve mollusk in the family Mytilidae that is heavily exploited as a food item via mariculture in Korea and China (Xu et al., 2010; FAO, 2011). However, the population of this endemic species is rapidly decreasing in Korea owing to overharvesting and habitat competition from the invasive species Mytilus galloprovincialis, which is believed to have been carried in the ballast water of ships from western Europe and is now the dominant cultivated species (Branch and Steffani, 2004; MIFAFF, 2012). The recovery of the population of this endemic species is urgent, but genetic information is required in order to improve understanding of the conservation, management, remediation, molecular phylogeny, population dynamics, and marker-assisted selective breeding of the species, which is currently limited (Xu et al., 2010). The development of polymorphic markers, such as microsatellites (MSs), would assist in obtaining genetic information regarding $M$. coruscus around the Korean Peninsula.

Among the diversity of available molecular markers, MSs, also known as simple sequence repeats (SSRs), can be useful for genetic structure analysis, family identification, and parentage assignment. In combination with genetic improvements in breeding, MS markers have considerably improved the aquaculture of shellfish, including oysters, mussels, and abalones (Bierne et al., 1998; Holland, 2001; Li et al., 2003). Despite their many applications, the isolation of MSs by traditional methods requires tedious and time-consuming processes, including screening of genomic libraries with repetitive probes and sequencing of positive clones (Hamilton et al., 1999; Zane et al., 2002). A newly developed technology called next-generation sequencing (NGS), which is capable of generating several gigabases of sequence data in a single run, has revolutionized MS marker development. Individual reads with NGS can capture individual MSs and their flanking sequences for polymerase chain reaction (PCR) primer design. This new approach has proven to be effective for the development of MS markers from several aquatic organisms (Kang et al., 2012; Greenley et al., 2012; Wang et al., 2012).

Another approach to MS marker development is cross-species transfer of identified MS markers to closely related species. Transferable markers are especially useful for comparing closely related taxa in order to identify the mechanisms involved in population divergence and speciation (Noor and Feder, 2006). Although the cross-species transferability of MS markers varies depending on the taxon, successful amplification within and even between genera has been reported for many organisms (Zhang and Hewitt, 2003; Barbará et al., 2007). 
One advantage of MS markers developed using the NGS technique is their higher crossspecies transferability, owing to the large number of candidate markers identified by pyrosequencing. Therefore, in the present study, MS markers for M. coruscus were developed using NGS techniques, and their cross-species transferability to other bivalves of the same family was tested.

\section{MATERIAL AND METHODS}

\section{Samples and DNA preparation}

Eighty-two wild M. coruscus samples were collected off the coast of Dokdo, the eastern-most Korean island in the East Sea. Muscle tissues from the samples were preserved in $100 \%$ ethanol at the sampling site and then transported to the laboratory for DNA extraction. Genomic DNA was isolated from each sample using a MagExtractor MFX-6100 automated DNA extraction system (Toyobo, Osaka, Japan). The extracted genomic DNA was quantified with a Nanodrop ND-1000 spectrophotometer (Thermo Fisher Scientific, Barrington, IL, USA) and stored at $-20^{\circ} \mathrm{C}$ until pyrosequencing. For the cross-species transferability test, DNA was extracted using the same method from ethanol-fixed tissues, which had been stored at the National Fisheries Research and Development Institute (Busan, Korea), of 7 related species belonging to the family Mytilidae.

\section{DNA sequencing}

DNA sequencing was conducted using the 454 pyrosequencing technology on a Genome Sequencer FLX-454 System (GS FLX sequencer; 454 Life Sciences, Branford, CT, USA) with a Pico TiterPlate (454 Life Sciences). Purified DNA was used for library construction after it was sheered three times. Sample preparation and DNA sequencing were performed according to manufacturer instructions (Roche Diagnostics, Mannheim, Germany). Sequencing was conducted at the National Instrumentation Center for Environmental Management (Seoul National University, Seoul, Korea).

\section{Sequence assembly and SSR findings}

The raw data from the sequencer system were assembled using the Newbler 2.6 software. To identify SSRs in the genomic sequence, the assembled contig consensus sequences and the unassembled singleton sequences were merged. The sequence was filtered for highquality scores using Less Useful Chunks Yank (LUCY) 1.20 p, and a modified SSR_finder. pl Perl program was used to find SSRs with dinucleotide and trinucleotide repeats. A total of 176 SSRs containing CA, CT, or AT repeats were randomly selected, and a primer set flanking each SSR was designed using the Primer3 software (available at http://bioinfo.ut.ee/primer3/). BLAST (available from the NCBI) was used to test for primer redundancy, using an e-value cutoff $\leq 0.001$.

\section{PCR and genotyping}

The performance of the 176 designed primer sets was tested using DNA from two indi- 
viduals of Mytilus coruscus. The PCR products were electrophoresed on a 1.5\% agarose gel, and 64 (36.4\%) primer sets yielded PCR products of 100-200 bp. Twenty of these primer sets were labeled and used to amplify DNA from 82 individuals. The forward primer of each pair was 5'end labeled with the fluorescent dyes 6-FAM, NED, and HEX (Life Technologies, Carlsbad, CA, USA). PCR was performed in a $10-\mu \mathrm{L}$ reaction mixture containing $0.25 \mathrm{U}$ Ex Taq DNA polymerase (Takara Biomedical, Inc., Shiga, Japan), 1X PCR buffer, $0.2 \mathrm{mM}$ dNTPs, 10 pmol of each primer, and 100 ng template DNA, using a PTC 200 DNA Engine (MJ Research, Waltham, MA, USA). The PCR conditions were as follows: $11 \mathrm{~min}$ at $95^{\circ} \mathrm{C} ; 35$ cycles each of $1 \mathrm{~min}$ at $94^{\circ} \mathrm{C}, 1$ min at the annealing temperatures shown in Table 1 , and $1 \mathrm{~min}$ at $72^{\circ} \mathrm{C}$; and a final extension of 5 min at $72^{\circ} \mathrm{C}$. MS polymorphisms were detected using an ABI PRISM 3130 XL Automated DNA Sequencer (Applied Biosystems, Foster City, CA, USA), and alleles were designated according to PCR product size relative to a molecular size marker (Genescan 400 HD ROX; Life Technologies).

Table 1. Characteristics of Mytilus coruscus microsatellite loci.

\begin{tabular}{|c|c|c|c|c|c|c|c|c|c|}
\hline Primer & Primer sequency & $\mathrm{Ta}$ & Motif & $\begin{array}{l}\text { No. of } \\
\text { alleles }\end{array}$ & $\begin{array}{c}\text { Allele } \\
\text { richness }\end{array}$ & $\begin{array}{l}\text { Range of } \\
\text { PCR }\end{array}$ & $H_{\mathrm{O}}$ & $H_{\mathrm{E}}$ & $F_{\text {IS }}$ \\
\hline Mc25-nfrdi & $\begin{array}{l}\text { NED: TTTCTTGTGCATTAAACCTCCT } \\
\text { CAGATATGTACGTGCCTTCGTA }\end{array}$ & 54 & $(\mathrm{CA})_{10}$ & 3 & 3.0 & $228-232$ & 0.062 & 0.130 & $0.523 *$ \\
\hline Mc31-nfrdi & $\begin{array}{l}\text { HEX: TGTGTGTCCACATATCCCTAAA } \\
\text { TCAGAAAAGGAACTGAAAAGGA }\end{array}$ & 54 & $(\mathrm{AT})_{10}$ & 15 & 12.9 & $151-197$ & 0.646 & 0.821 & 0.214 * \\
\hline Mc32-nfrdi & $\begin{array}{l}\text { 6-FAM: TGAGTATACGCATATGGTCCAA } \\
\text { TCAGAAAAGGAACTGAAAAGGA }\end{array}$ & 54 & $(\mathrm{AT})_{15}$ & 22 & 19.3 & $90-156$ & 0.613 & 0.901 & $0.320^{*}$ \\
\hline Mc46-nfrdi & $\begin{array}{l}\text { NED: GACATGACTTTTGTGTTGGTTG } \\
\text { CGAGATTCATTCATCATCATTC }\end{array}$ & 54 & $(\mathrm{AT})_{11}$ & 8 & 7.8 & $161-195$ & 0.141 & 0.727 & $0.807^{*}$ \\
\hline Mc65-nfrdi & $\begin{array}{l}\text { HEX: TTGTTGACATCGTTGTTGTTCT } \\
\text { TGAAACATCAATTACAAGTGCC }\end{array}$ & 54 & $(\mathrm{AG})_{14}$ & 13 & 12.4 & $172-196$ & 0.699 & 0.892 & $0.217^{*}$ \\
\hline Mc68-nfrdi & $\begin{array}{l}\text { 6-FAM: ATGAAGTATCACCCGTCTTGTC } \\
\text { GCTAATGCAGTGTCTTTCATCA }\end{array}$ & 54 & $(\mathrm{AG})_{8}$ & 1 & 1.0 & 117 & - & - & - \\
\hline Mc81-nfrdi & $\begin{array}{l}\text { NED: ATTACTAAGTCGTGGCCAAAAG } \\
\text { AATCACAAAGCATACAATAATAGCA }\end{array}$ & 54 & $(\mathrm{AT})_{9}$ & 11 & 9.8 & $209-227$ & 0.438 & 0.803 & $0.455^{*}$ \\
\hline Mc84-nfrdi & $\begin{array}{l}\text { NED: TAAAATCAATAAATGTCCCGCT } \\
\text { ACAACAGTTCAAATGTCATTGC }\end{array}$ & 54 & $(\mathrm{AT})_{8}$ & 4 & 3.6 & $153-159$ & 0.133 & 0.196 & $0.318^{*}$ \\
\hline Mc103-nfrdi & $\begin{array}{l}\text { 6-FAM: GTCATTGCCCTAATGTCAATCT } \\
\text { TAGACAAGTAGGGTGGGAGAAA }\end{array}$ & 60 & (AT) & 12 & 12.0 & $100-176$ & 0.278 & 0.692 & $0.598 *$ \\
\hline Mc117-nfrdi & $\begin{array}{l}\text { 6-FAM: GGGGCATCATATGTAAAATAGGT } \\
\text { CCTGGAACCATGTGTAAAGATT }\end{array}$ & 58 & $\left(C_{1}\right.$ & 7 & 6.6 & $142-156$ & 0.524 & 0.731 & $0.283 *$ \\
\hline Mc126-nfrdi & $\begin{array}{l}\text { NED: AGGCGAAGGATACTAAAAGGAC } \\
\text { CTCCGATAATTCTTCTTCATCG }\end{array}$ & 58 & $(\mathrm{AT})_{8}$ & 8 & 7.4 & $185-221$ & 0.564 & 0.684 & 0.175 \\
\hline Mc130-nfrdi & $\begin{array}{l}\text { NED: AAACCCCTCAAATTACAGCAC } \\
\text { GTCGGATTGTTACACACCTTTT }\end{array}$ & 54 & (AT & 10 & 9.0 & $247-273$ & 0.720 & 0.739 & 0.027 \\
\hline Mc131-nfrdi & $\begin{array}{l}\text { 6-FAM: TGACCAAATAAACCAATGAGAA } \\
\text { CAATTGCATATTTTTCGGATTT }\end{array}$ & 58 & $\Delta \mathrm{T}$ & 14 & 14.0 & $120-146$ & 0.268 & 0.851 & $0.671^{*}$ \\
\hline Mc136-nfrdi & $\begin{array}{l}\text { HEX: AGCGATGAAAAAGGGTTATGTA } \\
\text { CATTTTGCTGTGAAATCAAGTT }\end{array}$ & 58 & $(\mathrm{AT})_{12}$ & 21 & 19.7 & $121-173$ & 0.480 & 0.900 & $0.467 *$ \\
\hline Mc137-nfrdi & $\begin{array}{l}\text { 6-FAM: AATGTTCCATGCTAGTGTTCAA } \\
\text { CTTATCACAACACAGGTAGGCA }\end{array}$ & 58 & $(\mathrm{AT})_{9}$ & 6 & 6 & $134-144$ & 0.476 & 0.482 & 0.012 \\
\hline Mc154-nfrdi & $\begin{array}{l}\text { 6-FAM: ATTCTCCCCGTCTGAAATCTAT } \\
\text { GTCCTATCGTGGACATGATTCT }\end{array}$ & 58 & (AT & 1 & .0 & 140 & - & - & - \\
\hline Mc166-nfrdi & $\begin{array}{l}\text { 6-FAM: AACATGGACTTACCCATTTCTG } \\
\text { AATGAAACTTACAGGTGCACAA }\end{array}$ & 58 & $(\Delta T)$ & 13 & 12.2 & $131-171$ & 0.179 & 0.586 & 4* \\
\hline Mc169-nfrdi & $\begin{array}{l}\text { NED: TATTGAGTGTTTTTGAGAGGGG } \\
\text { TACTGCATGATTTTTGCTCATC }\end{array}$ & 54 & $(\mathrm{AT})_{9}$ & 6 & 53 & $237-247$ & 0.450 & 0.625 & $0.280^{*}$ \\
\hline Mc172-nfrdi & $\begin{array}{l}\text { HEX: TTAGGCAAATACCCTTAGGTGA } \\
\text { CTTTTGAAAATTCTGGATCTGC }\end{array}$ & 58 & $(A T)$ & 2 & 2.0 & $162-166$ & 1.000 & 0.503 & $-0.988 *$ \\
\hline Mc174-nfrdi & $\begin{array}{l}\text { NED: AAGTTTTCCAATCGAACAAAAA } \\
\text { GCTGCCTGTGCATACCTTAT }\end{array}$ & 58 & $(\mathrm{AT})_{8}$ & 20 & 19.4 & $127-241$ & 0.413 & 0.890 & $0.537 *$ \\
\hline
\end{tabular}

$H_{\mathrm{O}}$ and $H_{\mathrm{E}}=$ observed and expected heterozygosities; $F_{\mathrm{IS}}=$ inbreeding coefficient. ${ }^{*} F_{\mathrm{IS}}=$ significant deviation from Hardy-Weinberg expectation $(\mathrm{P}<0.05)$. 


\section{RESULTS}

\section{Summary of pyrosequencing results}

The pyrosequencing results are presented in Table 2. A total of 626,586 reads with an average length of $537 \mathrm{bp}$ were obtained by NGS, and 7,701 contigs were assembled from these reads by using Newbler 2.6. The total number of bases covered by these contigs was $4,440,387$. In addition, unassembled singleton sequences accounting for 478,808 bases were obtained. A total number of 473,309 reads, representing a total read length of $264,057,768$ $\mathrm{bp}$, remained after trimming the low-quality sequences, which were searched for SSRs. The numbers of reads for each dinucleotide repeat were 25,391 for AT, 5,725 for CA, 2,705 for CT, and 38 for GC. A total of 5,562 trinucleotide repeats were identified, and their sequences are shown in Table 2.

\begin{tabular}{|c|c|c|c|}
\hline Primary sequence data & & & Number \\
\hline Total reads & & & 626,586 \\
\hline Total bases & & & $336,215,470$ \\
\hline Contigs & & & 7,701 \\
\hline Bases & & & $4,440,387$ \\
\hline Singleton sequences & & & 478,808 \\
\hline Total reads after trimmed & & & 473,309 \\
\hline Total read-length after trimmed & & & $264,057,768$ \\
\hline Dinucleotide & Number & Dinucleotide & Number \\
\hline AT & 25,391 & $\mathrm{CT}$ & 2,705 \\
\hline CA & 5,725 & $\mathrm{GC}$ & 38 \\
\hline Trinucleotide & Number & Trinucleotide & Number \\
\hline AAA & 39 & TAC & 43 \\
\hline AAT & 766 & TTG & 485 \\
\hline AAG & 152 & TTC & 231 \\
\hline AAC & 241 & TGA & 237 \\
\hline ATA & 669 & TGG & 57 \\
\hline ATG & 271 & TGC & 28 \\
\hline ATC & 249 & TCG & 61 \\
\hline AGA & 204 & TCC & 46 \\
\hline AGT & 47 & GAG & 33 \\
\hline AGG & 33 & $\mathrm{GAC}$ & 283 \\
\hline AGC & 17 & GTG & 31 \\
\hline ACA & 225 & GGG & 8 \\
\hline ACG & 227 & GGC & 29 \\
\hline $\mathrm{ACC}$ & 42 & GCG & 40 \\
\hline TAA & 626 & CAG & 36 \\
\hline \multirow[t]{2}{*}{ TAG } & 52 & CGG & 54 \\
\hline & 3,860 & & 1,702 \\
\hline
\end{tabular}

\section{Selection of SSRs}

Of the total 33,859 SSRs containing dinucleotide repeats, $75.0 \%$ contained AT repeats, $17.0 \%$ contained CA repeats, $7.9 \%$ contained CT repeats, and $0.1 \%$ contained GC repeats. Among these SSRs, 176 loci containing more than 8 repeats of CA, CT, or AT were selected for primer synthesis. These primer sets were tested in two individuals of $M$. coruscus, and $64(36.4 \%)$ primer sets produced PCR products of 100-200 bp. Twenty primer sets $(31.3 \%)$ showed clear amplification and were selected for further analysis in 82 individuals (Table 1). 


\section{Analysis of 20 loci}

PCR analysis of the selected 20 loci in 82 individuals revealed 18 polymorphic loci, with 2 to 22 alleles (mean, 10.8), and 2 monomorphic loci, Mc68 and Mc154. Allele richness ranged from 2.0 to 19.7, with a mean of 10.1. Null alleles were detected at all loci except for Mc130, Mc137, and Mc172. This affected the Hardy-Weinberg equilibrium, as the observed heterozygosity $\left(H_{\mathrm{O}}\right)$ was lower than the expected heterozygosity $\left(H_{\mathrm{E}}\right)$ at most loci. This is shown by the significantly positive $F_{\text {IS }}$ values at 14 of the 18 polymorphic loci (Table 1 ). Only one locus, Mc172, had a significantly negative $F_{\text {IS }}$ value. The positive $F_{\text {IS }}$ values at the other three loci were not significant $(\mathrm{P}<0.05)$.

\section{Cross-species transfer of MS markers}

Cross-species amplification of the 20 loci was conducted in seven related species of various genera in the family Mytilidae. As shown in Table 3, 11 of the 20 test loci were not amplified from any of the species tested. In contrast, the locus Mc65 was amplified from all of the species tested and was polymorphic in all of them. The monomorphic locus Mc68 was amplified in 5 of the 6 species (83.3\%), and was also monomorphic in three species. Among the species, M. galloprovincialis, which is in the same genus as M. coruscus, Lithophaga curta, and Hormomya mutabilis showed the highest transferability (25\%), but the five amplified loci were polymorphic only in M. galloprovincialis and $H$. mutabilis. In addition, $L$. curtus and $H$. mutabilis, which belong to different genera, showed amplification of the same loci, although the polymorphism pattern was different at each locus. Among the species tested, Septifer virgatus showed the lowest transfer rate $(10 \%)$.

Table 3. Cross-species amplification in related mussel species using the Mytilus coruscus microsatellite loci.

\begin{tabular}{|c|c|c|c|c|c|c|c|c|}
\hline \multirow[t]{2}{*}{ Locus } & \multicolumn{7}{|c|}{ Mytilidae species } & \multirow[b]{2}{*}{$\begin{array}{c}\text { Transferability } \\
(\%)^{*}\end{array}$} \\
\hline & $\begin{array}{l}\text { Mytilus } \\
\text { coruscus } \\
(\mathrm{N}=82) \\
\end{array}$ & $\begin{array}{c}\text { Mytilus } \\
\text { galloprovincialis } \\
(\mathrm{N}=263)\end{array}$ & $\begin{array}{c}\text { Modiolus } \\
\text { agripetus } \\
(\mathrm{N}=3) \\
\end{array}$ & $\begin{array}{l}\text { Septifer } \\
\text { virgatus } \\
(\mathrm{N}=3)\end{array}$ & $\begin{array}{c}\text { Lithophaga } \\
\text { curta } \\
(\mathrm{N}=3) \\
\end{array}$ & $\begin{array}{c}\text { Hormomya } \\
\text { mutabilis } \\
(\mathrm{N}=7)\end{array}$ & $\begin{array}{c}\text { Musculista } \\
\text { senhousia } \\
(\mathrm{N}=2) \\
\end{array}$ & \\
\hline Mc25-nfrdi & $228-232$ & - & - & - & 229 & $229-291$ & 229 & $50.0(50.0)$ \\
\hline Mc31-nfrdi & $151-197$ & - & - & - & - & - & - & - \\
\hline Mc32-nfrdi & $90-156$ & - & - & - & - & - & - & - \\
\hline Mc46-nfrdi & $161-239$ & - & - & - & - & - & - & - \\
\hline Mc65-nfrdi & $172-196$ & $160-232$ & $183-191$ & 183-191 & $183-191$ & $181-193$ & $183-191$ & $100.0(100.0)$ \\
\hline Mc68-nfrdi & 117 & - & $105-117$ & 121 & 117 & $105-117$ & 143 & $83.3(33.3)$ \\
\hline Mc81-nfrdi & $209-271$ & - & - & - & - & - & - & - \\
\hline Mc84-nfrdi & $153-159$ & 143-199 & - & - & - & - & - & $16.7(100.0)$ \\
\hline Mc103-nfrdi & $100-240$ & - & - & - & - & - & - & - \\
\hline Mc117-nfrdi & $142-156$ & - & - & - & - & - & - & - \\
\hline Mc126-nfrdi & $185-221$ & - & - & - & - & - & - & - \\
\hline Mc130-nfrdi & $247-273$ & - & 121 & - & $129-171$ & $81-147$ & $167-219$ & $66.7(80.0)$ \\
\hline Mc131-nfrdi & $120-146$ & - & - & - & - & - & - & - \\
\hline Mc136-nfrdi & $121-173$ & - & - & - & - & - & - & - \\
\hline Mc137-nfrdi & $134-144$ & $130-174$ & - & - & - & - & - & $16.7(100.0)$ \\
\hline Mc154-nfrdi & 140 & - & - & - & 135 & $183-333$ & - & $33.3(33.3)$ \\
\hline Mc166-nfrdi & $131-171$ & - & - & - & - & - & - & - \\
\hline Mc169-nfrdi & $237-247$ & $221-273$ & - & - & - & - & - & $16.7(100.0)$ \\
\hline Mc172-nfrdi & $162-166$ & $160-186$ & - & - & - & - & - & $16.7(100.0)$ \\
\hline Mc174-nfrdi & $127-279$ & - & - & - & - & - & - & - \\
\hline Transferability $(\%)^{*}$ & $100.0(90.0)$ & $25.0(100.0)$ & $14.3(66.7)$ & $10.0(50.0)$ & $25.0(40.0)$ & $25.0(100.0)$ & $20.0(50.0)$ & \\
\hline
\end{tabular}

*Numbers in parentheses represent the percentage of polymorphic loci. including M. coruscus. 


\section{DISCUSSION}

M. coruscus is an economically important mussel species in Korea as well as in China due to its high nutritional value and good commercial price. However, the population of this species is decreasing rapidly as a result of overexploitation and the invasion of a more competitive species, $M$. galloprovincialis. Genetic information regarding M. coruscus is necessary for resource management and future artificial production of juveniles; however, very little information is currently available, probably because the distribution of this species is limited to parts of China, Korea, and Japan (Xu et al., 2010; Ye et al., 2012).

The establishment of MS markers would provide useful genetic tools for studying $M$. coruscus, but the most widely used method for developing MS markers is expensive and labor intensive. In the present study, to overcome this major limitation, we used NGS techniques to develop 20 MS markers for $M$. coruscus and to examine the transferability of these markers to related mussel species.

NGS techniques have been applied successfully for the development of MS markers in several marine organisms (Kang et al., 2012; Greenley et al., 2012; Wang et al., 2012). One advantage of NGS for MS marker development is that a large number of candidate sequences can be selected even with stringent criteria. For example, we selected 176 loci from among 33,859 candidate sequences that contained 8 or more dinucleotide repeats (Table 2). Because we had such a large number of candidate sequences, we were able to choose the primer sets that produced the clearest bands. In contrast, only 47 repeat-containing colonies could be identified in an enriched genomic library (Xu et al., 2010). The mean number of alleles for the 18 polymorphic loci in the present study was 10.8 , which contrasts with the 4.4 alleles reported by Xu et al. (2010).

In the analysis of the 18 polymorphic loci in $82 \mathrm{M}$. coruscus individuals, $H_{\mathrm{E}}$ was higher than $H_{\mathrm{O}}$ at most loci, resulting in positive $F_{\text {IS }}$ values, and indicating an excess of homozygotes. An excess of homozygotes has previously been reported in bivalves (Volckaert and Zouros, 1989). Although heterozygote deficiency can result from diverse factors such as inbreeding, the Wahlund effect, and selection, the main cause is generally the presence of non-amplifying PCR null alleles (Hoffman and Amos, 2005; Selkoe and Toonen, 2006), as the non-amplified heterozygotes are scored as homozygotes. Null alleles are usually suspected when the deviation from Hardy-Weinberg equilibrium occurs only in a particular locus (Panova et al., 2008).

In our study, null alleles were detected at all but three (Mc130, Mc137, and Mc172) of the loci. Thus, other factors such as founder effects or inbreeding of this isolated population are possible reasons for the excess of homozygotes in M. coruscus. The sampling site at Dockdo is located $217 \mathrm{~km}$ from the Korean Peninsula and $87 \mathrm{~km}$ from the nearest island, Ulleung-Do. Like other mussel species, $M$. coruscus generally inhabits the upper part of littoral zones and shallow sub-littoral areas (Distel, 2000). Although they fertilize by releasing eggs and sperm that can travel some distance, little genetic exchange with other population is expected. The possible genetic isolation of this population and the reasons for the homozygote excess could be further explored by comparing its genetic structure with that of other populations or by using statistical methods (Panova et al., 2008).

The cost effectiveness of MS marker development can be enhanced by transferring markers identified in one species to related species. The large number of MS candidates identified by pyrosequencing can be especially useful in cross-specific marker transfer, as has been shown for several species (Kang et al., 2012; Wang et al., 2012). The taxonomic range and 
taxonomic group are the primary factors affecting marker transferability. In a previous survey, Barbará et al. (2007) reported that the mean percentages of amplification and polymorphism between species within the same genus were 73 and $65 \%$, respectively, whereas these percentages between genera within the same family were 60 and $43 \%$, respectively. In our study, the amplification percentage in $M$. galloprovincialis, which belongs to the same genus as $M$. coruscus, was $25.0 \%$, and all of the transferred markers showed polymorphism (Table 3 ). In the other five genera of the same family, the mean percentages of amplification and polymorphism were 18.9 and $61.3 \%$, respectively.

The transferability percentages in our study are much lower than those reported in some other organisms, but are similar to those reported by Li et al. (2011). In the development of MS markers for M. galloprovincialis by cross-species transfer of MS markers from related species, Li et al. (2011) identified one of 14 markers for M. coruscus and 5 of 10 markers for Mytilus edulis as being successfully amplified in M. galloprovincialis.

Evolutionary distance between the source and target species is another important factor affecting the success of cross-species amplification and the probability of a source locus being polymorphic in the target species (Primmer et al., 2005). This can be observed in a Mytilidae species phylogenetic tree that was constructed based on the sequences of the cytochrome c oxidase subunit I gene (Figure 1). Although M. coruscus and M. galloprovincialis belong to the same genus, the genetic distance between these two species was similar to that observed between the other species pairs tested in this study. Therefore, the low marker transferability that we reported here may reflect the genetic distances among these species.

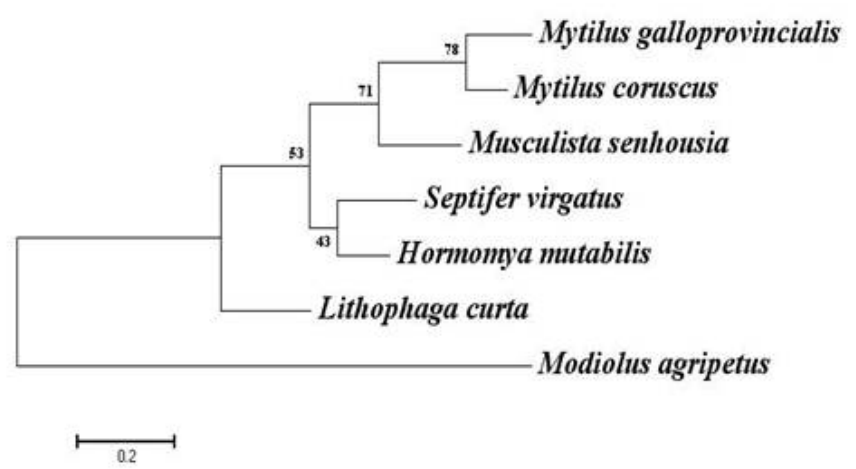

Figure 1. Neighbor-joining tree of Mytilidae species constructed based on sequences of the cytochrome c oxidase subunit I gene. Numbers near the nodes indicate bootstrap support values.

In a survey of marker transfer studies, it was noted that attempts to transfer markers for endemic species have been very limited, probably due to the difficulty in obtaining samples from suitable specimens (Barbará et al., 2007). Here, we tested marker transferability among seven species of the family Mytilidae. Except for M. galloprovincialis, which was introduced from Europe, the species are all endemic to the areas around the Korean Peninsula. Although the numbers of specimens of some species were limited because of the difficulty in obtaining samples, this information will nevertheless be useful for future molecular marker studies on the Mytilidae. 


\title{
ACKNOWLEDGMENTS
}

\author{
Research supported by grants from the National Fisheries Research and Development \\ Institute (NFRDI) of Korea.
}

\section{REFERENCES}

Barbará T, Palma-Silva C, Paggi GM, Bered F, et al. (2007). Cross-species transfer of nuclear microsatellite markers: potential and limitations. Mol. Ecol. 16: 3759-3767.

Bierne N, Launey S, Naciri-Graven Y and Bonhomme F (1998). Early effect of inbreeding as revealed by microsatellite analyses on Ostrea edulis larvae. Genetics 148: 1893-1906.

Branch GM and Steffani CN (2004). Can we predict the effects of alien species? A case-history of the invasion of South Africa by Mytilus galloprovincialis (Lamarck). J. Exp. Mar. Biol. Ecol. 300: 189-215.

Distel DL (2000). Phylogenetic relationships among Mytilidae (Bivalvia): 18S rRNA data suggest convergence in mytilid body plans. Mol. Phylogenet. Evol. 15: 25-33.

FAO (2011). National Aquaculture Sector Overview: Republic of Korea. FAO Fisheries and Aquaculture Department. Available at [http://www.fao.org/fishery/countrysector/naso_korea/en]. Accessed December 1, 2012.

Greenley AP, Muguia-Vega A, Saenz-Arroyo A and Micheli F (2012). New tetranucleotide microsatellite loci in pink abalone (Haliotis corrugata) isolated via 454 pyrosequencing. Conserv. Genet. Resour. 4: 265-268.

Hamilton MB, Pincus EL, Di Fiore A and Fleischer RC (1999). Universal linker and ligation procedures for construction of genomic DNA libraries enriched for microsatellites. Biotechniques 27: 500-507.

Hoffman JI and Amos W (2005). Microsatellite typing errors: approaches, common sources and consequences for paternal exclusion. Mol. Ecol. 14: 599-612.

Holland BS (2001). Invasion without a bottleneck: Microsatellite variation in natural and invasive populations of the brown mussel Perna perna (L.). Mar. Biotechnol. 3: 407-415.

Kang JH, Park JY and Jo HS (2012). Rapid development of microsatellite markers with 454 pyrosequencing in a vulnerable fish, the mottled skate, Raja pulchra. Int. J. Mol. Sci. 13: 7199-7211.

Li H, Liang Y, Sui L, Gao X, et al. (2011). Characterization of 10 polymorphic microsatellite markers for Mediterranean blue mussel Mytilus galloprovincialis by EST database mining and cross-species amplification. J. Genet. 90: e30-e33.

Li Q, Park C, Kobayashi T and Kijima A (2003). Inheritance of microsatellite DNA markers in the Pacific abalone Haliotis discus hannai. Mar. Biotechnol. 5: 331-338.

MIFAFF (2012). Ministry for Food, Agriculture, Forestry and Fisheries of Korea. Fisheries Information Service, Annual Statistics of Fisheries Production. Available at [http://www.fips.go.kr]. Accessed January 8, 2013.

Noor MA and Feder JL (2006). Speciation genetics: evolving approaches. Nat. Rev. Genet. 7: 851-861.

Panova M, Mäkinen T, Fokin M, André C, et al. (2008). Microsatellite cross-species amplification in the genus Littorina and detection of null alleles in Littorina saxatilis. J. Mollus. Stud. 74: 111-117.

Primmer CR, Painter JN, Koskinen MT, Palo JU, et al. (2005). Factors affecting avian cross-species microsatellite amplification. J. Avian Biol. 36: 348-360.

Selkoe KA and Toonen RJ (2006). Microsatellites for ecologists: a practical guide to using and evaluating microsatellite markers. Ecol. Lett. 9: 615-629.

Volckaert F and Zouros E (1989). Allozyme and physiological variation in the scallop Placopecten magellanicus and a general model for the effects of heterozygosity on fitness in marine molluscs. Mar. Biol. 103: 51-61.

Wang J, Yu X, Zhao K, Zhang Y, et al. (2012). Microsatellite development for an endangered bream Megalobrama pellegrini (Teleostei, Cyprinidae) using 454 sequencing. Int. J. Mol. Sci. 13: 3009-3021.

Xu TJ, Sun YN, Yuan YT, Liao Z, et al. (2010). Isolation and characterization of polymorphic microsatellite loci in the hard-shelled mussel, Mytilus coruscus (Mytilidae). Genet. Mol. Res. 9: 1388-1391.

Ye YY, Li JJ, Wu CW, Xu MY, et al. (2012). Genetic analysis of mussel (Mytilus coruscus) populations on the coast of East China Sea revealed by ISSR-PCR markers. Biochem. Syst. Ecol. 45: 1-6.

Zane L, Bargelloni L and Patarnello T (2002). Strategies for microsatellite isolation: a review. Mol. Ecol. 11: 1-16.

Zhang DX and Hewitt GM (2003). Nuclear DNA analyses in genetic studies of populations: practice, problems and prospects. Mol. Ecol. 12: 563-584. 